\title{
Energy Efficient Three-Phase Utility Interactive Residential Microgrid with Mode Transfer Capabilities at Weak Grid Conditions
}

\author{
Shailendra Kumar, Member, IEEE, Bhim Singh, Fellow, IEEE, Bikash C. Pal, Fellow, IEEE, \\ Lie Xu, Senior Member, IEEE and Ahmed Al-Durra, Senior Member, IEEE
}

\begin{abstract}
This paper presents an energy efficient autonomous grid synchronized photovoltaic (PV) arraybattery energy storage (BES) based microgrid with power quality improving capabilities under weak grid conditions. The microgrid is developed to supply consumer loads even at disappearance of the weak grid. The BES is not only beneficial on daily energy saving but it is also sized to furnish smoothening facilities to the PV-BES microgrid. A pseudo-linear synchronization scheme is used, which is based on extraction of fundamental positive sequence components from the polluted grid voltages. The islanded controller furnishes reliability by maintaining the voltage and frequency and continuous power to the consumer load. The multi-variance generalized adaptive controller is proposed to control the microgrid and to improve the power quality aspects. The effectiveness of microgrid is demonstrated experimentally with estimation of phase and frequency at grid synchronization and de- synchronization with polluted grid conditions.
\end{abstract}

Index Terms- PV array, BES, utility synchronization, power quality and microgrid.

\section{INTRODUCTION}

Recently, microgrids based on the renewable energy and storage have received wide attentions because of their autonomous operation, increased efficiency, ease of control and compactness [1]. However, energy management scheme is the key challenge for an autonomous operation of a microgrid. A residential microgrid with optimal energy management scheme with vehicle to grid facility, is proposed in [2]. A hybrid microgrid with the power management scheme, is presented in [3], which has also discussed the issue of independent power sharing. A microgrid works in either grid tied mode or standalone mode based on the accessibility of the grid. Aviles et.al [4] have presented a utility interfaced microgrid with fuzzy logic control including the renewable energy sources and storage for residential electrification. However, for interaction of these microgrids to the main utility grid, the estimations of fundamental grid voltage, phase angle and frequency, play a significant role under grid voltage perturbation, harmonics pollution and voltages unbalancing [5]-[6]. The phase locked loops (PLLs) are the extensively trusted schemes for

\footnotetext{
Manuscript received 09-Jan-2019; revised on April. 07, 2019 and June 27, 2019 and accepted 02-Aug-2019. This work was supported by the MIETY, DST, Govt. of India, RP03391G and EPSRC- EP/K03619X/1.

S. Kumar and A. Al-Durra are with Advanced Power and Energy Center, EECS Department, Khalifa University of Science \& Technology, Abu Dhabi. B. Singh is with the EED, Indian Institute of Technology Delhi, New Delhi, India. B. Pal is with EEED, Imperial College London and L. Xu is with EEED, University of Strathclyde, Glasgow. (E-mail:er.dwivedi88@gmail.com)
}

synchronization of power converters to the main utility grid. However, the accuracy and response of conventional PLL, are deteriorated at polluted grid conditions [7]. Therefore, grid synchronization and de-synchronization are important challenges, which have also been found in [8]. A new adaptive notch filtering technique for grid synchronization, is reported in [9]. The proposed technique is robust and PLL is not required for synchronization. Few attempts of islanding detection and grid synchronization for the grid connected converter have been found in [10]-[11]. In [10], the authors have developed a unit templates based synchronizing technique to connect the voltage source converter (VSC) to the main grid. However, the reported system has not the capability to operate at failure of utility. In [11], the reported system has worked well in both the modes of operation. Moreover, criteria and identical standard for sharing of energy of distributed resources to the main distribution grid, have been found in [12]. The power requirement in rural areas in night time, is slightly low as compared to evening and morning peaks. Therefore, at disappearance of PV source and distribution grid, the battery can take care of loads at night. Therefore, microgrid with PV generation and a storage, furnishes the opportunity to feed a small consumer load for long hours overnight utilizing a BES bank and, as per the capacity of PV array, to envelop partly or fully the early day and mid-day load. In this paper, the BES is utilized as a backup to supply nonlinear loads at insufficient PV irradiance or complete outage of PV source and utility. Therefore, no external power is utilized to charge the BES bank. The import/export of battery storage power is controlled through the buck-boost converter [13].

In present days, power electronics loads have become the major concern of power quality disturbances in the distribution grid. The harmonics produced by nonlinear loads, cause maloperation of relay, overheating of magnetic core and disturbances in the communication network. In [14], a comprehensive research is carried out to identify the causes and to provide the cost effective retrofit solution for enhancement of power quality. In [15]-[17], various control strategies for harmonics mitigation are discussed with the control of PV system and hybrid PV-BES-utility system. The proposed topologies provide filtering activity like power factor improvement, load balancing, and harmonics mitigation and when PV array output is not available (during the night hours, cloudy and rainy season) than it works as a distribution static compensator (DSTATCOM) and provides filtering activity alone. In this way, the VSC can be utilized more efficiently and economically. Moreover, the IEEE-519 standard defines the power quality and limits of total harmonics distortion (THD) [18]. The motivation of this work, is to design and develop a 
multi-variance generalized adaptive (MVGA) controlled [19] PV-BES based three phase microgrid in order to feed the three phase loads with multimode operation at weak grid condition. In grid connected operation, a reliable synchronizing algorithm is needed for various industrial applications. Now a days, unbalanced nonlinear loads are increasing at point of common coupling (PCC), which make the synchronization process more challenging. In addition, a minimum variance adaptive filter is presented to control the three phase microgrid in grid tied mode to synchronize VSC to the utility. However, in islanded control mode, the phase, frequency and amplitude of load voltages are supervised by voltage control. The contribution of the proposed microgrid system is given as follows.

- The major contribution is demonstrated to supply uninterrupted power to the critical loads in grid tied and islanding modes. The microgrid is still operated even at disappearance of the grid only the algorithm is changed from MVGA control to voltage control. Hence, it enhances the operation adaptability of PV-BES microgrid.

- The MNRE (Ministry of New and Renewable Energy) has taken several steps for abutment of diesel generator (DG) set because it is very dangerous for human health. Therefore, to avoid the DG set, an energy storage is required to avoid the outage of electricity. The PV array with a battery and grid synchronization/de- synchronization is a good solution for a residential area.

- A mode transition is implemented using the information of utility voltage, phase and frequency. The proposed synchronization control enables smooth change of control scenarios from utility integrated to standalone and resynchronization without experiencing any spikes across load and to protect dedicated loads from severe faults.

- The microgrid operates even at variation of phase and frequency as per prescribed value at de-synchronization of the grid, reconnection and polluted grid conditions. The estimation of phase and frequency through PLL, experiences substantial variation at de-synchronization and resynchronization. However, the use of pseudo-linear enhanced phase locked loop (PL-EPLL) rectifies the drawbacks of conventional PLL. The evaluation of utility variation in phase and frequency PLL, experiences wide frequency and phase changes at fault in the grid. As frequency and synchronizing signals, are evaluated within a single loop [20].

- Using bidirectional static transfer switches (STS) for synchronization and de-synchronization, the reliability of the system is improved. Moreover, there is no need of bulky magnetic circuits/transformers for stepping up BES voltage.

\section{MICROGRID CONFIGURATION AND CONTROL APPROACHES}

The microgrid with a PV array, BES and distribution network, is shown in Fig. 1. Under the faulty condition, the voltage falls rapidly below a particular value. Therefore, the microgrid is isolated from the distribution network and islanding process takes place. Apart from the injection of active power to the main grid, a compensator provides the functionalities of improved power quality. The problem of oscillations, is resolved by integrating the battery due to the intermittery nature of $\mathrm{PV}$ array. For DC-AC conversion, a MVGA controlled converter with $\mathrm{AC}$ inductor, is selected. Moreover, the sharing of active and reactive powers by each component, is included in Table-I. The control techniques applied to microgrid with PV array and a storage, include current control and islanded control as

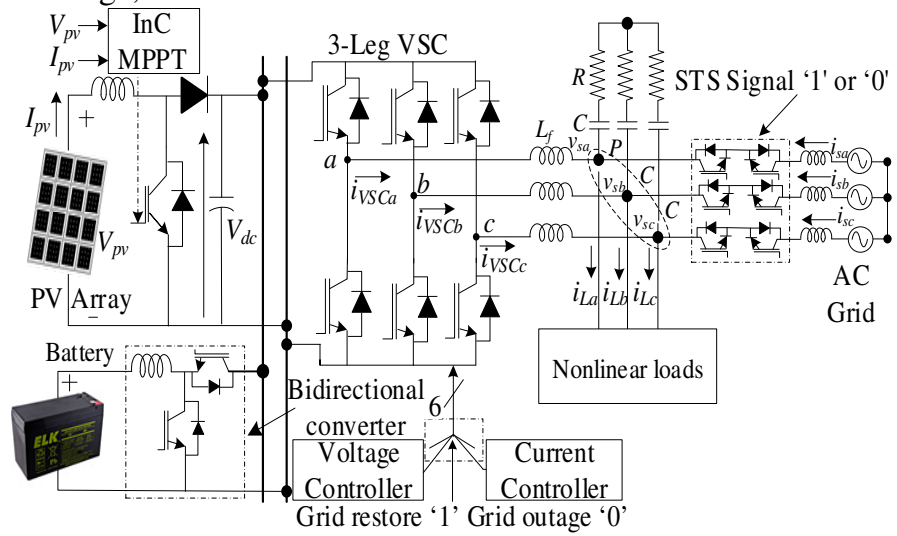

Fig. 1 Microgrid configuration

TABLE-I

\begin{tabular}{|c|c|c|c|}
\hline $\begin{array}{c}\text { Type of } \\
\text { Operating } \\
\text { modes }\end{array}$ & Components & $\begin{array}{l}\text { Sharing of } \\
\text { Active } \\
\text { Energy }\end{array}$ & $\begin{array}{l}\text { Sharing of } \\
\text { Reactive } \\
\text { Energy }\end{array}$ \\
\hline \multirow{4}{*}{$\begin{array}{l}\text { Grid } \\
\text { interactive } \\
\text { and } \\
\text { standalone } \\
\text { modes }\end{array}$} & PV Array & Active & - \\
\hline & $\begin{array}{l}\text { Battery Energy } \\
\text { Storage (BES) }\end{array}$ & Active & - \\
\hline & $\begin{array}{l}\text { Voltage source } \\
\text { converter (VSC) }\end{array}$ & Active & Reactive \\
\hline & Utility grid & Active & Reactive \\
\hline
\end{tabular}

shown in Fig. 2. Under sudden restoration of utility, the multivariance generalized adaptive (MVGA) based current controller is responsible for the active power injection and compensation of nonlinear load tied at PCC. At outage of utility, the voltage controller is activated and the microgrid feeds the power to the load and the battery (according to SOC $\%$ ). If the PV array generation is larger than the load demand and the battery SOC is maintained then the microgrid operates in off-MPPT mode. Here, the detailed description of current controller and mode transfer control, is presented here.

\section{A. Multi-Variance Generalized Adaptive (MVGA) Controller} The principle of extraction of active weight component $\left(W_{p L A}\right)$ of load currents, is based on variance rate and feed-forward concept, which is shown in Fig. 2. The proposed adaptive current controller mitigates the uncertainties, and accommodates the noise and disturbances recover the loop by feedback of the extracted component of load current. Moreover, the extracted component using adaptive controller, reaches desired value when the load currents are unspecified and/or varying in time. Here, the utility currents include four dominant parts: equivalent weight power of the load, losses of PV-BES microgrid, contribution of BES and PV array contribution.

1) Estimation of Unit Templates and Amplitude Peak Voltage The PCC sensed line voltages $\left(v_{s a b}, v_{s b c}\right)$ are used to get instantaneous phase voltage for three phases as,

$v_{s a}=\frac{2 v_{s a b}+v_{s b c}}{3}, v_{s b}=\frac{-v_{s a b}+v_{s b c}}{3}, v_{s c}=\frac{-v_{s a b}-2 v_{s b c}}{3}$ 


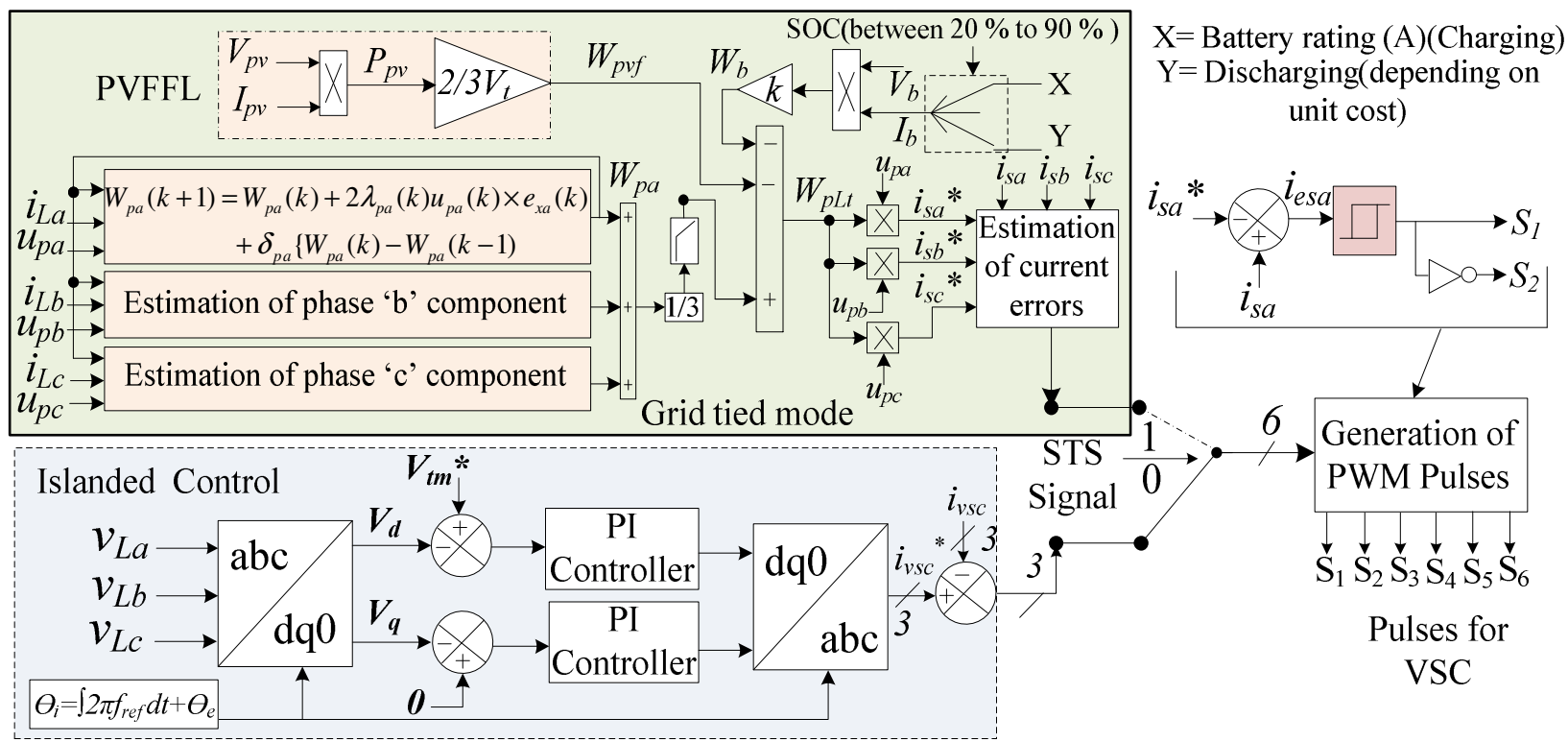

Fig.2 Control of VSC in utility tied and islanded mode

The peak of PCC voltage is calculated as,

$$
V_{t}=\sqrt{(2 / 3)\left(v_{s a}^{2}+v_{s b}^{2}+v_{s c}^{2}\right)}
$$

The in-phase unit vectors are computed using PCC voltages, which are given as,

$u_{p a}=\frac{v_{s a}}{V_{t}}, u_{p b}=\frac{v_{s b}}{V_{t}}, u_{p c}=\frac{v_{s c}}{V_{t}}$

\section{2) Fundamental Weight Extraction of Load Currents}

The MVGA based adaptive current controller is used to extract fundamental components of load currents. This algorithm enhances the speed of extraction of weights maintaining proper accuracy. The weight of the fundamental active component of load current of phase ' $\mathrm{a}$ ' $\left(\mathrm{i}_{\mathrm{La}}\right)$ is calculated as,

$$
\begin{gathered}
W_{p a}(k+1)=W_{p a}(k)+2 \lambda_{p a}(k) u_{p a}(k) \times e_{x a}(k) \\
+\delta_{p a}\left\{W_{p a}(k)-W_{p a}(k-1)\right. \\
e_{x a}(k)=\eta\left\{1-e^{-\alpha\left|e(k)^{2 *}(k-1)\right|}\right\}
\end{gathered}
$$

Where $\alpha, \eta, \delta$ are the gains of adaptive controller, which controls the steady state and transient response of current controller and $\mathrm{e}_{\mathrm{xa}}$ is the exponential factor for the controller.

The error between the estimated fundamental and input load current, is computed as,

$$
e_{p a}(k)=i_{L a}(k)-u_{p a}(k) * W_{p a}(k)
$$

where, $u_{p a}, i_{L a}$ and $W_{p a}$ are the in-phase unit template of phase ' $a$ ', load current of phase ' $a$ ' and weight of active reference component.

Similarly, the weights for fundamental active components of load currents of phase ' $b$ ' ( $\left.\mathrm{i}_{\mathrm{Lb}}\right)$ and 'c' ( $\left.\mathrm{i}_{\mathrm{LC}}\right)$ are estimated as,

$$
\begin{aligned}
W_{p b}(k+1)= & W_{p b}(k)+2 \lambda_{p b}(k) u_{p b}(k) \times e_{x b}(k) \\
& +\delta_{p b}\left\{W_{p b}(k)-W_{p b}(k-1)\right. \\
W_{p c}(k+1)= & W_{p c}(k)+2 \lambda_{p c}(k) u_{p c}(k) \times e_{x c}(k) \\
& +\delta_{p c}\left\{W_{p c}(k)-W_{p c}(k-1)\right.
\end{aligned}
$$

The load unbalancing is supervised by estimated average active weight, which is evaluated as [21],

$$
W_{p L A}=\left(W_{p a}+W_{p b}+W_{p c}\right) / 3
$$

3) Estimation of PV Feed-Forward and BES Contributions The estimated PV power is considered identical to utility power by assuming lossless PV inverter. Hence, the injection of generated $\mathrm{PV}$ power to the grid, is mathematically computed as, $W_{p v f}=2 P_{p v} /\left(3 \times V_{t}\right)$

Here, the voltage and current PI controllers are used to regulate the DC link voltage $\left(\mathrm{V}_{\mathrm{dc}}\right)$ and battery reference current $\left(\mathrm{I}_{\mathrm{b}} *\right.$ ). The DC link voltage across the capacitor, is sensed and the error between $\mathrm{V}_{\mathrm{dc}}$ and $\mathrm{V}_{\mathrm{dc}} *$ is estimated as,

$V_{d c e r r}=V_{d c} *-V_{d c}$

The estimated error is fed to the voltage PI controller to get the battery reference current $\left(\mathrm{I}_{\mathrm{b}} *\right)$ as,

$$
\begin{aligned}
I_{b} *(n+1)= & I_{b} *(n)+k_{p v}\left\{V_{\text {dcerr }}(n+1)-V_{\text {dcerr }}(n)\right\} \\
& +k_{i v} V_{\text {dcerr }}(n+1)
\end{aligned}
$$

Where $\mathrm{k}_{\mathrm{pv}}$ and $\mathrm{k}_{\mathrm{iv}}$ are proportional and integral gains of the PI controller.

This $\mathrm{I}_{\mathrm{b}} *$ is compared with the sensed battery current $\left(\mathrm{I}_{\mathrm{b}}\right)$ and the error is given to the PI current controller to estimate the duty ratio for the bidirectional converter as,

$$
\begin{aligned}
D(n+1)= & D(n)+k_{p i}\left\{I_{\text {berr }}(n+1)-I_{\text {berr }}(n)\right\} \\
& +k_{i i} I_{\text {berr }}(n+1)
\end{aligned}
$$

The MVGA based algorithm is also responsible to manage the charging/discharging of the battery bank. If the SOC is less than $90 \%$ then the battery is charged generally when the unit cost of the energy is low. Moreover, the battery is discharged and there is drop in the DC link voltage as PV array and the grid, disappear. Hence, the component of the BES is computed as,

$$
W_{b}=\left\{\left(2 V_{b} I_{b}\right) /\left(3 V_{t}\right)\right\}
$$

Where $V_{b}$ and $I_{b}$ are BES voltage and current. Under the unavailability of the utility grid, the three-phase microgrid is switched to the islanded mode seamlessly and the battery is controlled depending upon the PV generation and load demand. 


\section{4) Reference Grid Currents Generation}

For computation of net active component $\left(W_{p L t}\right)$, the average component is subtracted from the PVFF and BES contribution. Mathematically, it is formulated as,

$W_{p L t}=W_{p L A}-W_{p v f}-W_{b}$

The reference grid currents are found as,

$i_{s a}^{*}=W_{p L t} * u_{p a}, i_{s b}^{*}=W_{p L t} * u_{p b}, i_{s c}^{*}=W_{p L t} * u_{p c}$

\section{5) Generation of Gating Pulses for VSC}

To generate gating pulses for VSC, current error signals are estimated from the variation between reference grid currents $\left(i_{s a} *, i_{s b} * i_{s c} *\right)$ and sensed grid currents $\left(i_{s a}, i_{s b}, i_{s c}\right)$. The derived error is utilized to originate the gating sequences of VSC.

\section{B. State Space Based Mode Transition Approach}

The state space based mode transition approach comprises of an islanding detection unit to detect the outage of utility network monitoring the grid voltage, frequency and angle variation between the grid and load voltage, which is shown in Fig. 3. The state space mode transition approach based islanding detection unit sends a switch over signal (' 0 ' or ' 1 ') to the STS. The PV-BES microgrid switches from current control to voltage control mode at variation in the grid voltage, phase angle and frequency, which are larger than $\pm 10 \% \mathrm{~V}, \geq 3^{0}$ and $\pm 0.5 \mathrm{~Hz}$. The concept of state space based mode transition approach is based on the number of states and the response to transfer from one state to the other state. The mathematical model of state of mode transitions, is given as,

State space model $=(I, O, S, S i, T, F)$

where $\mathrm{I}$ and $\mathrm{O}$ are a set of input and output states; $\mathrm{S}$ is a set of finite states; $\mathrm{Si}$ is the initial state of the system; T represents the transition function and $\mathrm{F}$ is the output function. Thus, based on these conditions, the VSC is transferred from one mode to another based on conditions. Here, the PL-EPLL structure [22], is used to synchronize the PV-BES microgrid to the utility as presented in Fig. 4. The estimated phase angles $\left(\Theta_{\mathrm{s}}, \Theta_{\mathrm{L}}\right)$, frequency and amplitude of grid voltages from PL-EPLL structure, are monitored by the state space model and accordingly the grid fault is detected. The error between estimated phase angles $\left(\Theta_{\mathrm{s}}, \Theta_{\mathrm{L}}\right)$ are passed through the sine function to reduce the phase angle error between them. If grid parameters are not in prescribed limits then the grid fault is considered and the control is shifted from the current control to the voltage control. Simultaneously, state space based mode transition approach sends ' 0 ' it, the STS and microgrid are switched to the standalone mode. A vice-versa procedure is observed after clearing of fault and recovery of the grid. Hence, state space based technique determines the operating modes as per the given signals and delivers the output to the STS.

\section{Detection of Fundamental Positive Sequence Voltages at Polluted Grid Conditions}

The three phase grid voltages are converted to $\alpha \beta$ reference frame by utilizing the Clark transformation then given to the PL-EPLL control for estimation of harmonics free fundamental positive sequence components for the synchronization as shown in Fig. 5. The three phase polluted voltages are transformed into symmetrical coordinates by using the Fortescue's theorem [23]. Here, the microgrid is synchronized using the fundamental positive sequence voltages. The harmonic components in the grid voltages are mitigated using PL-EPLL based control. Moreover, a PL-EPLL algorithm [21] is also used for evaluation of grid voltage angle $\left(\theta_{\mathrm{s}}\right)$, load voltage angle $\left(\theta_{\mathrm{L}}\right)$ and grid and load voltages frequencies. The attributes of PLL and EPLL, depend on amplitude of input signal. If the input grid voltage is polluted, the PLL does not estimate the fundamental frequency and phase signals precisely, which is main limitation of PLL block. By utilizing pseudo-linear EPLL algorithm

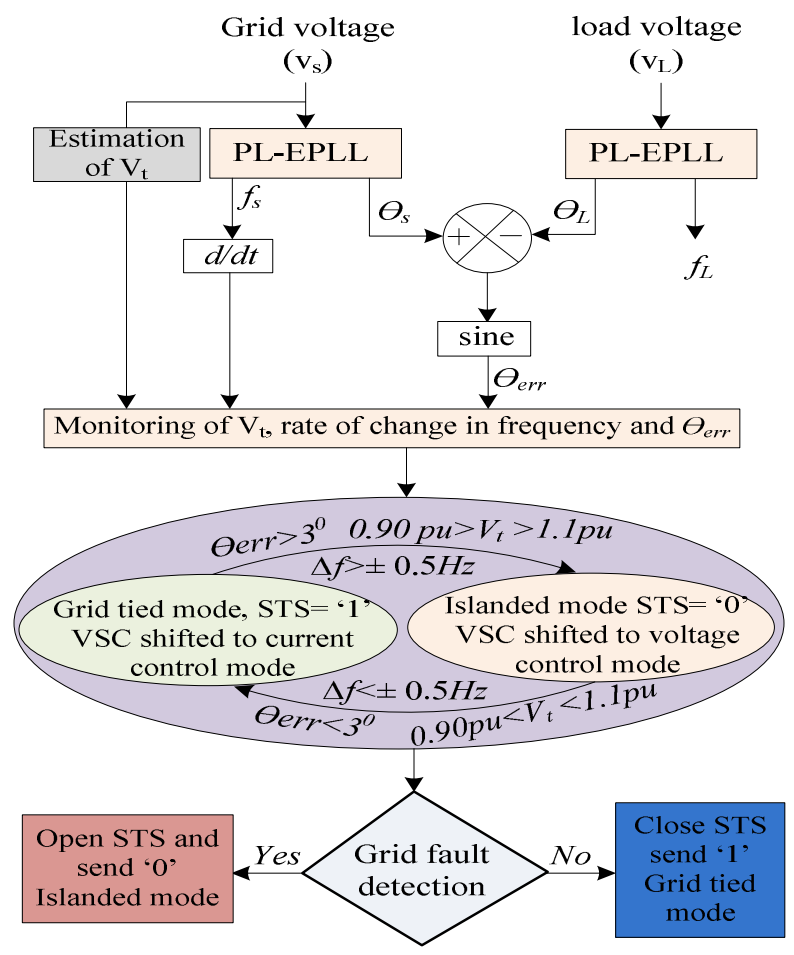

Fig.3 State space based mode transition approach

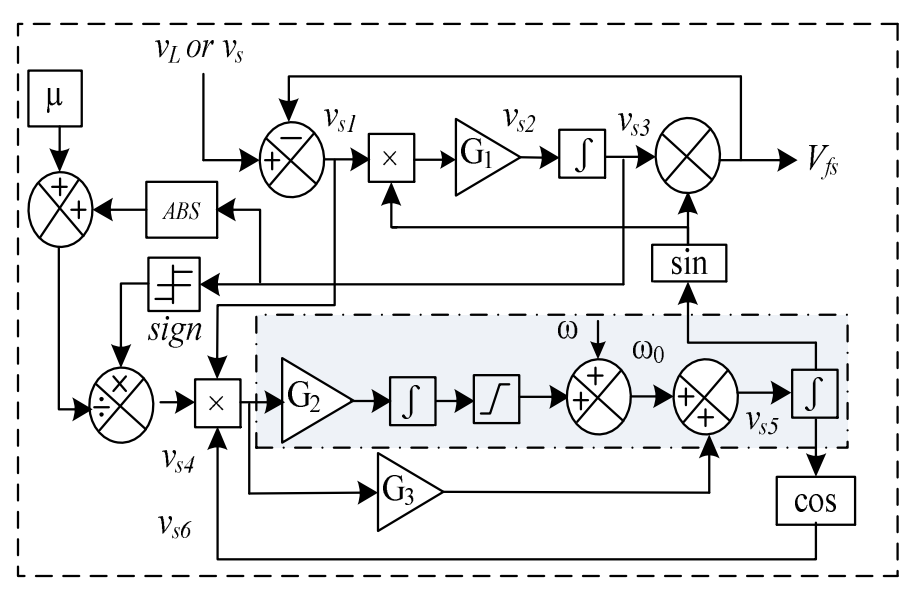

Fig.4 Structure of PL-EPLL based control

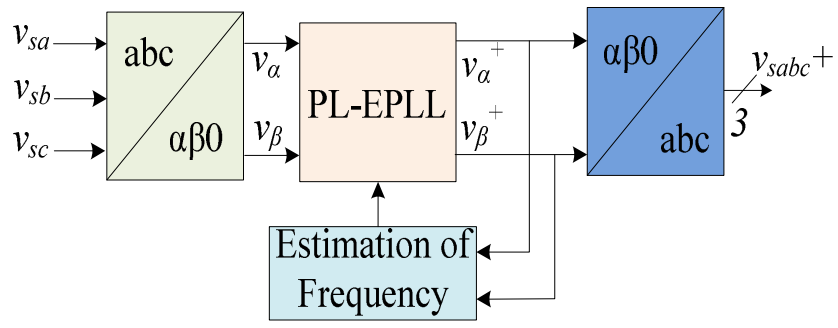

Fig.5 Estimation of positive sequence component using PL-EPLL control 
the drawback of PLL is avoided. Here, PL-EPLL algorithm also works as an adaptive filtering, therefore, the steady state error remains zero in frequency as well as in phase angle estimated through the PL-EPLL algorithm. Mathematically, the grid voltage components $\mathrm{v}_{\mathrm{s} l}, v_{s 2}, v_{s 3}, v_{s 4}$ and $\mathrm{v}_{s 5}$ from the PL-EPLL structure, are expressed as,

$$
\begin{aligned}
& v_{s a 1}=v_{s a}-v_{f s a} \\
& v_{s 2}=G_{1} *\left(v_{s a}-v_{f s a}\right) \operatorname{Sin} \theta \\
& v_{s 3}=\int v_{s 1} G_{1} \sin \theta d \theta
\end{aligned}
$$

Where $\Theta$ is evaluated phase angle error. The $\mathrm{v}_{s 4}$ is updated to make control operation tolerable, if the grid voltage is polluted and varying in nature. Such attributes are crucial where the input signal is not in the limit. Therefore, following equation presents the limit of input signal as,

$$
\begin{aligned}
& v_{s 4}=\frac{\operatorname{Sign}\left(v_{s 3}\right)}{\left|v_{s 3}\right|+\mu} \\
& v_{s 4}=\left\{\begin{array}{ll}
\frac{\operatorname{Sign}\left(v_{s 3}\right)}{\left|v_{s 3}\right|+\mu} & v_{s 3}{ }^{\min } \leq\left|v_{s 3}\right| \leq v_{s 3}{ }^{\max } \\
0 & \text { otherwise }
\end{array}\right\}
\end{aligned}
$$

Where sign $\left(\mathrm{v}_{\mathrm{s} 3}\right)$ constitutes a block, which estimate the sign of the input function of extracted grid voltage component $\left(v s_{3}\right), \mu$ is the small positive number and $v_{s 3}{ }^{m i n}$ and $\mathrm{v}_{\mathrm{s} 3}{ }^{\max }$ are minimum and maximum limits of grid voltage.

\section{RESULTS AND DISCUSSION}

The prototype of a microgrid consisting of PV array generation based renewable energy source with a battery energy storage and its control, is built and operated in grid tied and islanded mode based on the accessibility of the distribution grid. The insulated gate bipolar transistors (IGBTs) of Semikron (SKM200GB12V) make are utilized for DC/AC and DC/DC conversions. The MATLAB/Simulink models of control techniques are interfaced to the controller. The sensed quantities are given to the analog to digital (ADC) conversion set and digital I/O channels are used to get the pulse width

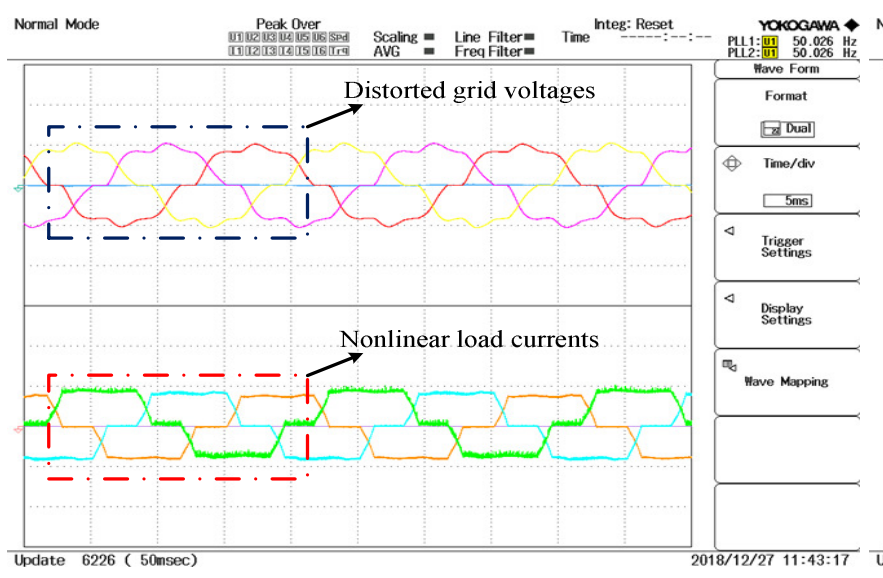

modulation (PWM) pulses of VSC. The parameters used in test, are illustrated in Appendix. The experimental rig developed in the laboratory along with the DSP (dSPACE-1103), programmable power supply for realizing the PV array, is demonstrated in Fig. 6.

\section{A. Assessment of Traditional PLL and PL-EPLL at Utility} Synchronization With Polluted Grid Conditions

Fig. 7 shows the distorted grid voltages, nonlinear load currents and respective percentage of harmonics in grid voltages and load current at adverse grid conditions. The PL-EPLL control is configured to estimate the fundamental component of grid voltages. However, using the PL-EPLL based robust control, irrelevant harmonics components are mitigated and fundamental components are extracted. Fig. 8 shows the comparative assessment of conventional and proposed controller under sudden grid recovery scenarios. The polluted grid voltage $\left(v_{s a}\right)$, the extracted fundamental voltage through the PL-EPLL $\left(v_{f a}\right)$ and grid voltage angles using PLL and PL-EPLL $\left(\theta_{P L L}, \theta_{P L-E P L L}\right)$ at sudden availability and unavailability of the utility grid, are explained through Figs. 8 (a)-(b). The extracted voltage is nearly sinusoidal with good dynamic response at appearance and disappearance of the utility grid, which show the magnificent filtering capability of proposed control. The variation in grid voltage angle estimated through PLL, is clearly visible, which introduces the chattering effect and deteriorates the synchronization process. However, the grid voltage angle estimated through PL-EPLL control is smooth and error free.

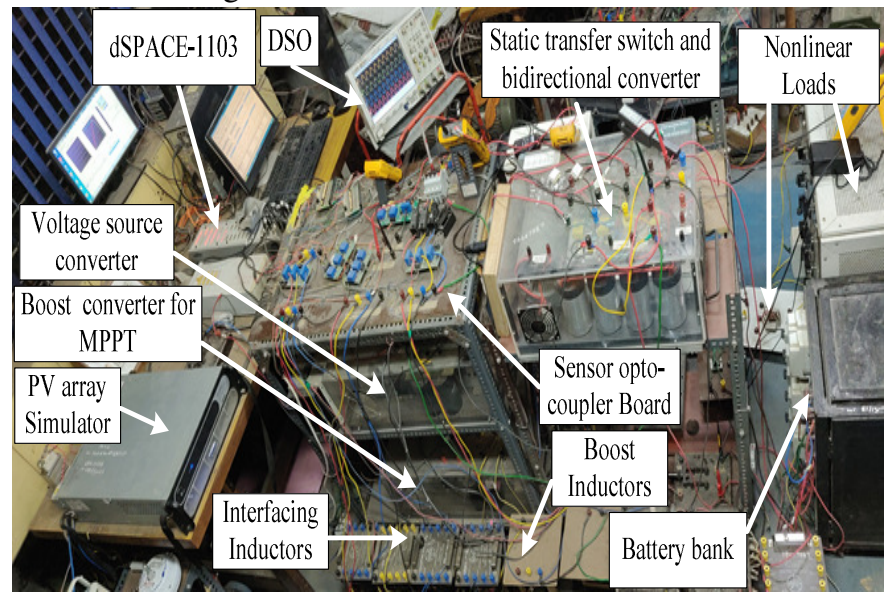

Fig.6 Prototype developed in the laboratory

Fig.7 Distorted grid voltages, load currents and respective THD in grid voltages and load currents at adverse grid conditions 


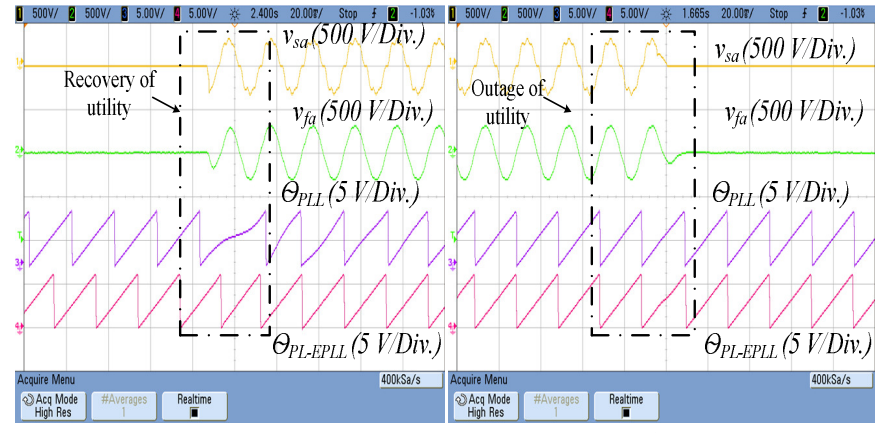

(a)

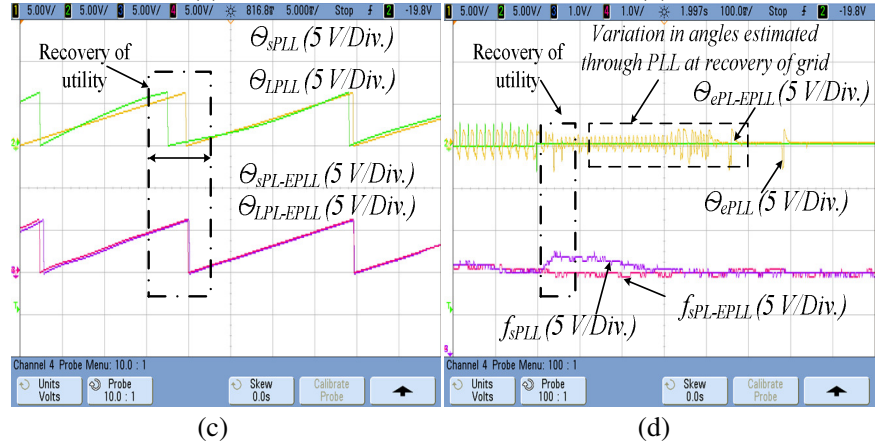

Fig. 8 Comparative analysis of phase and frequency through PLL and PL-EPLL (a)-(b) Distorted $v_{s a}$, estimated fundamental grid voltage $\left(v_{f a}\right)$, angles estimated through PLL and PL-EPLL (c) grid and load voltage angles (d) variation in phase error and frequencies at sudden recovery of utility

Moreover, at outage of utility, there is no change in grid voltage angle estimated with conventional PLL and PL-EPLL control. Figs. 8 (c)-(d) present the evaluated phase angles, phase angle errors and variation in frequencies by using conventional PLL and PL-EPLL controls at sudden appearance of the polluted grid. It is observed that the difference in angles determined using PLL, is substantial. However, PL-EPLL is accurate enough to provide less difference between the load and grid voltage angles at sudden appearance of the grid. The frequencies are also estimated through PLL and proposed control. The frequency tracking capability of proposed control, is fast enough and there is no variation in the frequency extracted using the PL-EPLL control. However, there is around $2 \mathrm{~Hz}$ frequency variation evaluated through the PLL and takes five to six cycles to reach the steady state at recovery of the utility grid.

\section{B. Assessment of Proposed Current Controller as Compared to Traditional Algorithm}

Fig. 9 shows the assessment of proposed and traditional current controllers. Here, response is compared for these controllers experimentally in order to demonstrate the steady state and dynamic accuracy. It is observed that the dynamic response of proposed current controller is good, which is shown in Fig. 9. Moreover, the overshoot and undershoot of the DC link voltage, are influenced by the sudden connection and disconnection of the load. Therefore, for this application the dynamic response of the controller must be good to avoid the overshoot and under shoot in the DC link voltage.

\section{Synchronization of Microgrid to the Main Utility}

Figs.10 (a)-(b) show the synchronization performance of the microgrid at sudden grid availability. The response is validated through the grid voltage $\left(v_{s a}\right)$, load voltages $\left(v_{L a}\right)$, grid and load

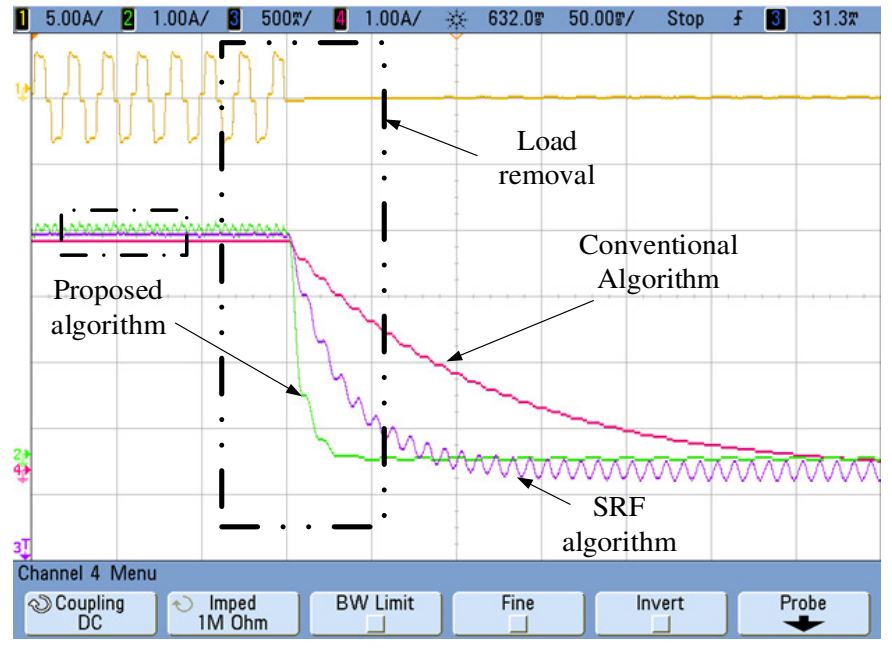

Fig. 9 Steady state and dynamic response of current controllers

currents $\left(i_{s} \& i_{L}\right)$. Under utility appearance, angle, frequency and amplitude of $v_{s}, v_{L}$ are observed by state space based mode transition approach and STS switches to ' 1 ' on at appearance of the grid. However, switching pulses of VSC, are supervised by MVGA based current controller and feeds excess power to the distribution network. It is observed that the load current is not interrupted at sudden appearance of distribution network and utility current appears as the grid is connected to the microgrid. The VSC carries only load power before appearance of distribution grid. The VSC current is increased and has also furnished load compensation as the utility is connected. Under appearance of distribution network, the mode of the battery is transferred to non-operation mode from the charging mode.

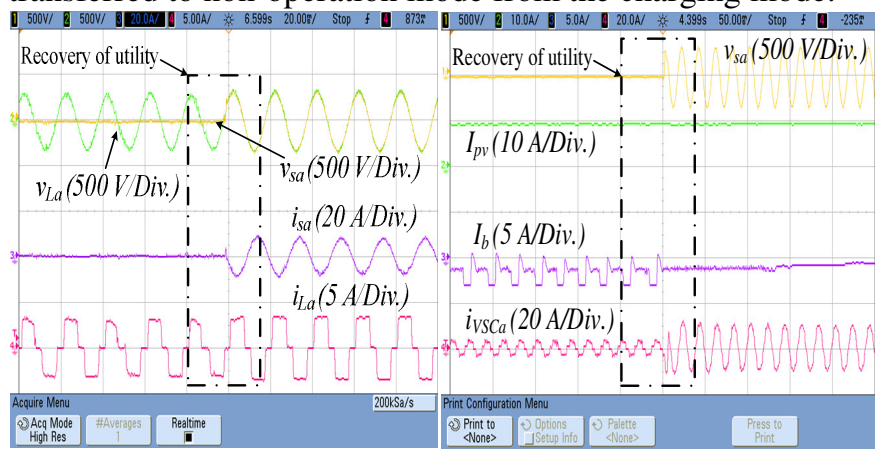

(a)

(b)

Fig.10 (a)-(b) Synchronization of microgrid with the main utility

D. De-synchronization of Microgrid with Main Utility

Figs.11 (a)-(b) show the response of microgrid at grid outage appearance. The response is validated by showing the grid and load voltages $\left(\mathrm{v}_{\mathrm{sa}} \& \mathrm{v}_{\mathrm{La}}\right)$, grid current $\left(\mathrm{i}_{\mathrm{sa}}\right)$ and load current $\left(\mathrm{i}_{\mathrm{La}}\right)$ as depicted in Fig. 11 (a). The system is shifted to the standalone mode from the grid connected operating mode, when the grid voltage reduces from a particular voltage level and the STS signal is switched to ' 0 ' from ' 1 ' as the grid voltages are vanished. In this scenarios, the microgrid must be disconnected from the main grid. However, the PV array delivers continuous power to the local load without any interruption as the load current is steady even in mode transfer. For this purpose, the microgrid that is developed to provide surplus power to the grid, is generally required to have autonomous functionality. The extraction of PV power remains same throughout the process as the surplus energy is utilized to charge the BES bank in islanded 
operation as shown in Fig. 11 (b). As the microgrid is switched to the islanding, the battery starts charging and VSC carries only power required by loads.

\section{E. Behaviour of Microgrid at Constant Power Mode}

Fig. 12 presents the behavior of microgrid for feeding constant power at weak grid conditions. The three phase distorted grid voltages and nonlinear load currents applied in the microgrid are presented in Fig. 12 (a). However, after compensation, the three phase voltages $\left(v_{s}\right)$ and grid currents $\left(i_{s}\right)$ are balanced, sinusoidal and out of phase (as power is being fed to the grid) as shown in Fig. 12 (b). Fig. 12 (c) shows $v_{s}$ and VSC currents, which mitigate the harmonics of load currents and hence, the utility currents are sinusoidal. The harmonics spectra of distorted utility voltage THD $(11.31 \%)$ and load current THD $(22.80 \%)$ before the compensation are shown in Fig. 12(d). However, after the compensation, in Fig. 12(e), the harmonics percentage of grid voltage and current, are found below 5\%, which shows the fundamental extraction and harmonic-

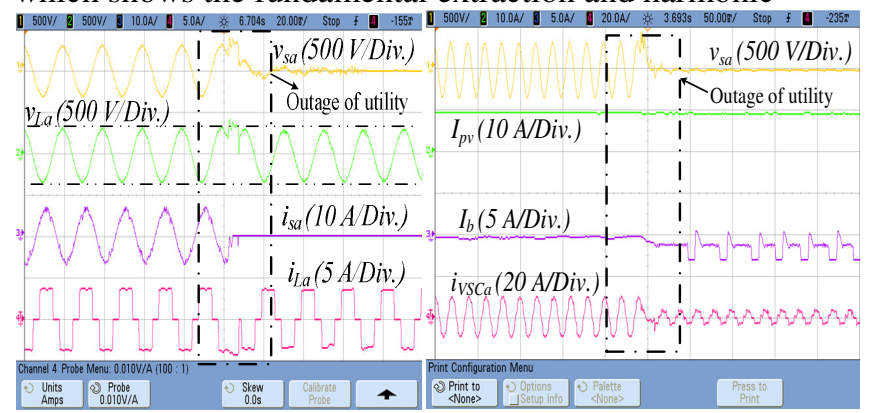

(a)

(b)

Fig.11 (a)-(b) De-synchronization of microgrid with the main utility rejection robustness capability of proposed controls. The supplied power to the grid, is presented in Fig. 12(f). The crest PV power is fed to the grid at close to unity power factor.

\section{F. Performance of Microgrid at Interruption and} Appearance of $P V$ Generation and Grid

The behavior of system at interruption and recovery of PV generation, is presented in Figs. 13 (a)-(d).The performance is validated by exhibiting PV current $\left(I_{p v}\right)$, utility current $\left(i_{s a}\right)$, VSC current $\left(i_{V S C a}\right)$, DC link voltage $\left(V_{b}\right)$, battery current $\left(I_{b}\right)$, battery voltage $\left(V_{b}\right)$ and grid voltage in Figs. 13 (a)-(b). At interruption of PV generation, the current from the PV array, is vanished. However, the distribution network is still connected so the system works as a DSTATCOM and VSC carries only harmonics currents and provides power quality compensation. Moreover, the direction of $i_{s a}$ is changed as now the grid starts supplying energy to the load. As the utility is available so it keeps the BES in non-operating zone. Moreover, the behavior of micorgrid at recovery of PV source, is shown in Figs. 13 (c)(d). After recovery of PV source, VSC carries the active power extracted from the PV array as well as the harmonics power. The DC link voltage and grid voltage, are sustained to their prescribed limit even under failure of PV generation. After disconnection of PV array in night, the grid may also disappear in rural areas, hence, Figs. 13 (e)-(f) present the experimental results of microgrid at the grid failure and restoration. At these scenarios, the residential microgrid is shifted to islanding and the VSC is controlled by the voltage control technique. The BES starts exporting energy to supply critical loads in interruption of both PV array and the grid. After the recovery of utility, the load is fed by the grid and the battery reaches the

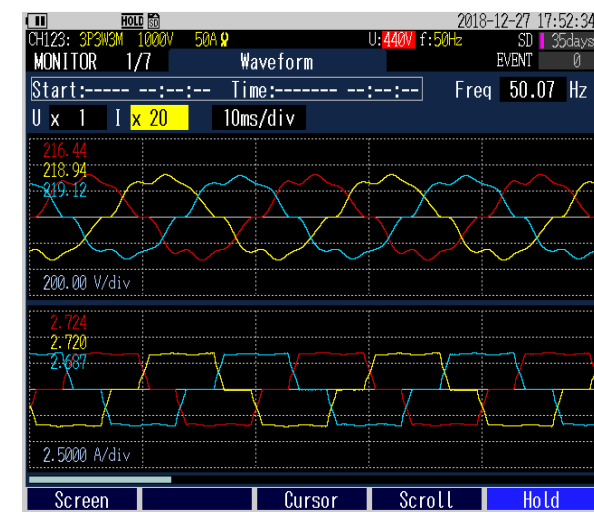

(a)

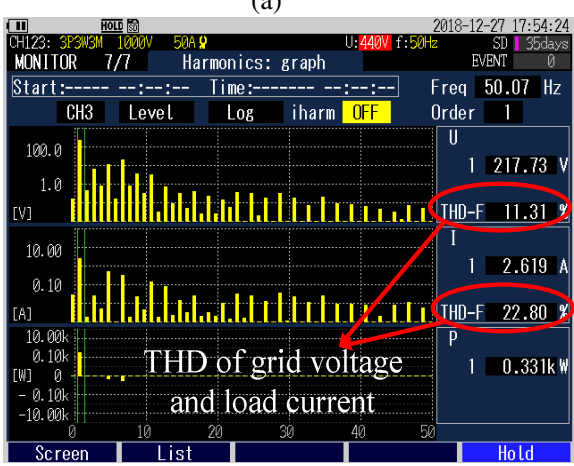

(d)

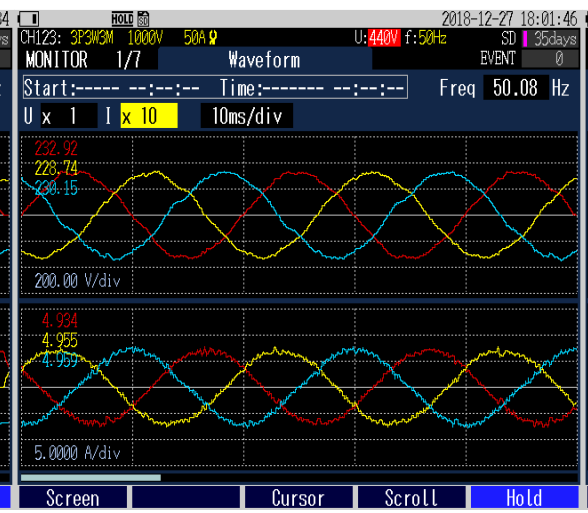

(b)

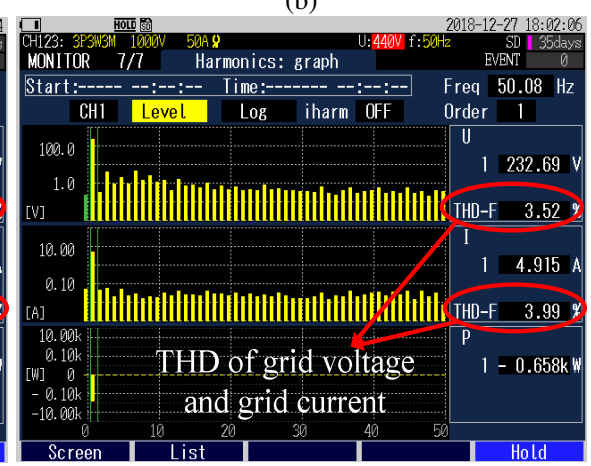

(e)

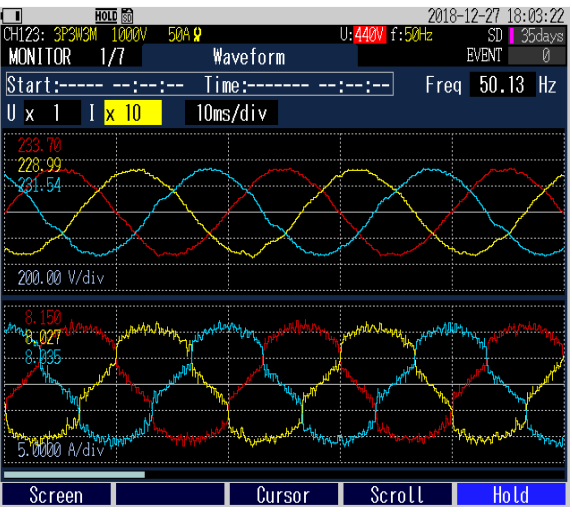

(c)

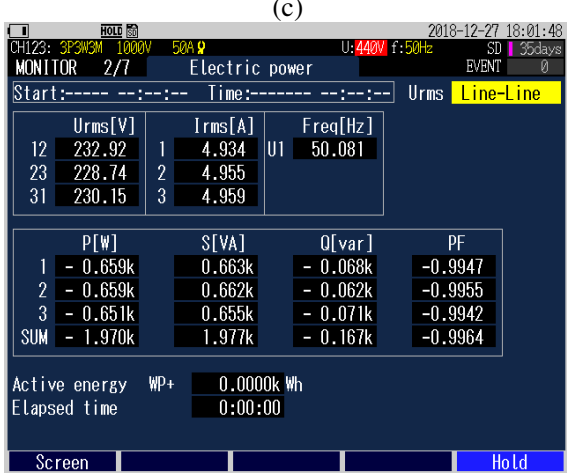

(f)

Fig. 12 Behavior of microgrid for feeding constant power at weak grid conditions (a) distorted grid voltages $\left(v_{s}\right)$ and load current $\left(i_{L a}\right)$, (b) Grid voltages $\left(v_{s}\right)$ and grid currents $\left(i_{s}\right)$ after compensation (c) VSC currents $\left(i_{V S C}\right)$ (d) THD of $v_{s a}$ and $i_{s a}$ before compensation (e) Harmonic spectrum of $v_{s a}$ and $i_{s a}$ after the compensation (f) surplus PV power injected to the utility 


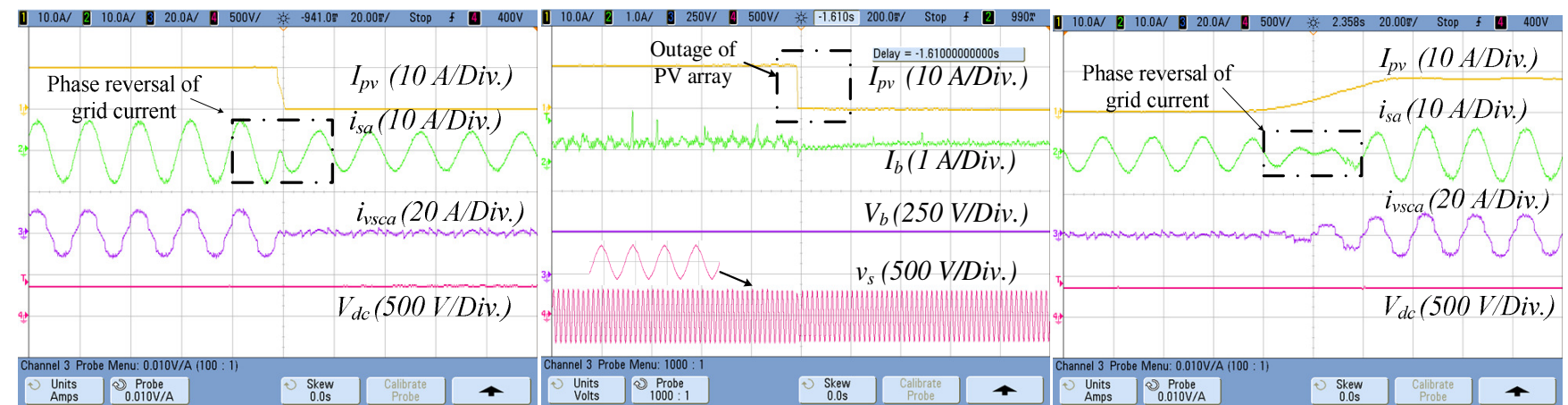

(a)

(b)

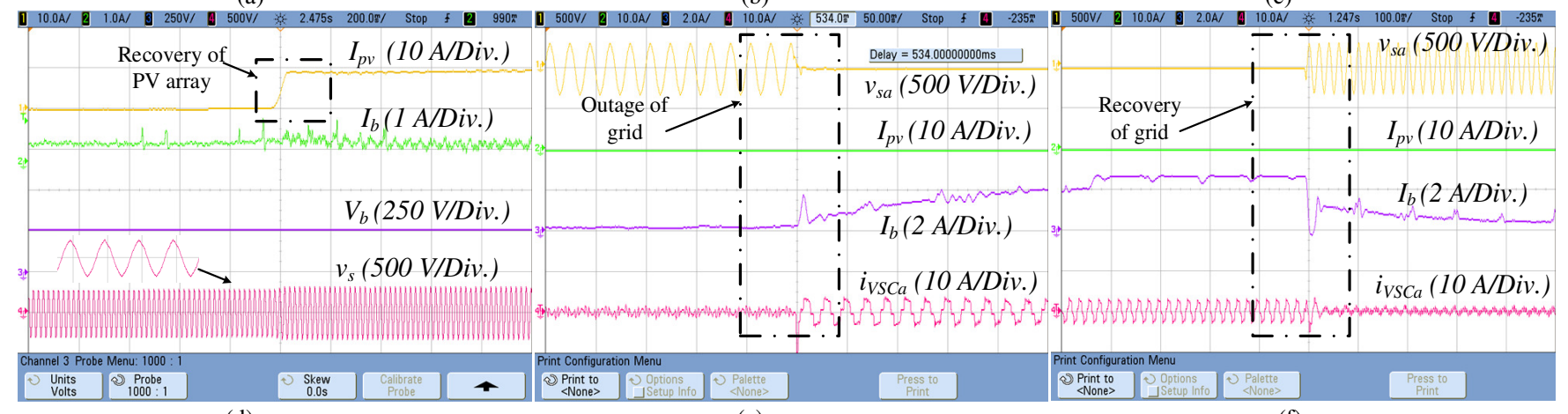

(d) (e) (f)

Fig. 13 (a)-(f) Behavior of microgrid at outage and recovery of PV generation and utility

floating mode. Moreover, under all operating scenarios, attributes of power quality are always maintained.

\section{G. Performance in Standalone Mode}

Figs. 14 (a)-(f) show the experimental analysis of load voltages in standalone mode along with their harmonics spectra. Under grid connected mode, the magnitude of grid voltage is around $230 \mathrm{~V}$ and therefore, magnitude and frequency are maintained by the grid. However, after outage of utility grid, the load voltages are also maintained to $230 \mathrm{~V}$ by providing the reference frequency to the control, which is shown in Figs. 14 (a)-(c). Moreover, the harmonics distortion is also less than 5\% as per the IEEE-519 standard. Therefore, it is realized that the PCC voltage remains same in both the modes of operation under highly nonlinear load.
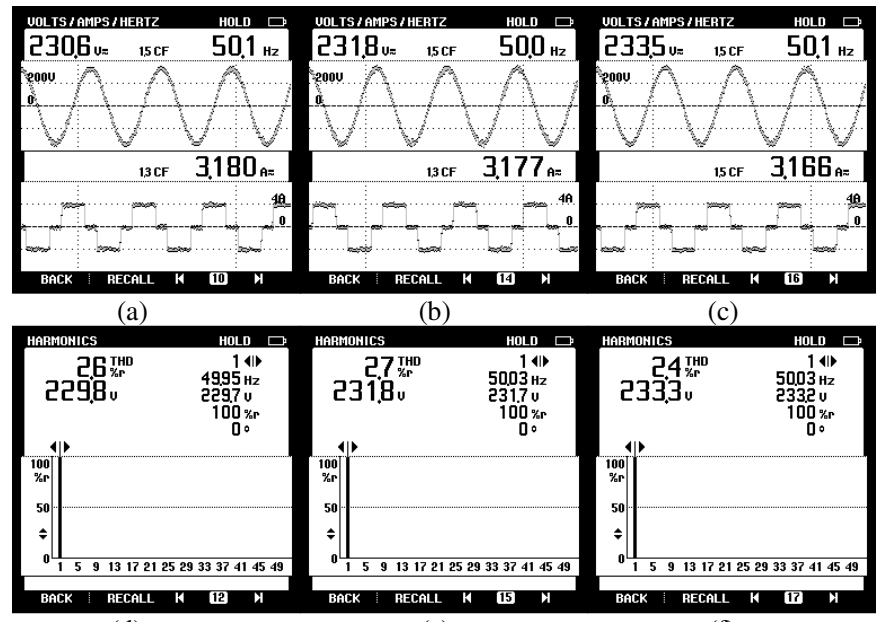

(d)

(e)

(f)

Fig. 14 (a)- (f) Magnitude of load or PCC voltage $\left(\mathrm{v}_{\mathrm{La}}, \mathrm{V}_{\mathrm{Lb}}, \mathrm{V}_{\mathrm{Lc}}\right)$ in islanded mode along with harmonics analysis

\section{CONCLUSIONS}

Experimental response of proposed microgrid has demonstrated the transient free switching from one mode to other and harmonics mitigation because of nonlinear load. Under transitions from grid interactive to islanding and light load to large load and vice-versa operations, the proposed algorithm has mitigated the transient and distortion across the critical loads. The microgrid has also mitigated the power quality issues because of variety nonlinear loads along with extraction of maximum power, and ensures the optimum utilization of PV array and BES. The fundamental goals have been achieved, namely, accurate estimation of fundamental component, injection of extracted PV array power to the grid, and suppression of harmonics. The MVGA based algorithm has been utilized in utility connected mode. Although, a state space based transition approach with PL-EPLL control for mode transitions, has been executed at utility appearance and disappearance. The microgrid has been tested and verified in order to show the behavior at various conditions.

\section{Appendix-I}

\section{APPENDICES}

Experimental data: PV array MPP power $=3.5 \mathrm{~kW}$, PV MPP voltage $=350 \mathrm{~V}$, PV MPP current=10 A, Boost inductor $=4.5$ $m \mathrm{H}$, BES parameters $=240 \mathrm{~V}$ and $7 \mathrm{Ah}$, bidirectional inductor $=$ $5 m \mathrm{H}, f_{s}=10 \mathrm{kHz}$, VSC: capacitor $\left(\mathrm{C}_{\mathrm{dc}}\right)=2250 \mu \mathrm{F}$, three phase utility $=230 \mathrm{~V}, 50 \mathrm{~Hz}$, Grid Impedance: $\mathrm{R}_{\mathrm{s}}=0.2 \Omega, \mathrm{L}_{\mathrm{s}}=5 \mathrm{mH}$ Interfacing inductors $=5 \mathrm{mH}$, ripple filter $=6 \Omega, 12 \mu \mathrm{F}$, Voltage PI regulator $=0.2$ and 0.01 , Current PI regulator $=0.1 \& 0.001$, current controller gains $\alpha=0.2, \eta=0.1$ and $\delta=0.4$

\section{Appendix-II}

The Comparisons with Related and Available Literature

1) In this work, a two stage topology is investigated. In available literatures, a single stage topology is investigated. 
The advantages of single stage system is that it does not require the boost converter, therefore, free from the inductor and switching losses, in which both the functions (extraction of maximum power and control of battery charging/discharging) are achieved by the bidirectional converter. However, selection of IGBT device is according to the open circuit voltage of PV array as it is larger in case of single stage system, which is one of major constraint of the single stage system. Moreover, under sudden change in the insolation from $1000 \mathrm{~W} / \mathrm{m}^{2}$ to $200 \mathrm{~W} / \mathrm{m}^{2}$, there is significant drop in the DC link voltage, which does not maintain required performance of PV-BES microgrid. Therefore, to address above issues in this work, a two stage topology is selected so that the DC link is decoupled from the PV array via a boost converter.

2) The method of extraction of fundamental active component of load current is new. The proposed controller is compared with the conventional controllers experimentally in order to demonstrate the steady state and dynamic responses. It is observed that the dynamic response of current controller used in this work is good.

3) Here, a dq based voltage controller is used to control the microgrid in islanded mode. Here, a PI controller is used in dq components, which are DC quality. However, in [17], a $\mathrm{PI}$ controller is used in AC voltage error (after subtraction of generated reference sinusoidal load voltage and sensed sinusoidal load voltage), which may lead to error in tracking of fundamental load voltage.

4) In [6] [9] and [17], the proposed topology and control are verified experimentally by considering the ideal grid voltages. However, under grid voltage distortions, it may lead to wrong synchronization and the system may fail to operate. In this work, the proposed topology is tested under ideal as well as in distorted grid voltages conditions by modifying the control only.

5) In this work, a pseudo-linear -enhanced phase locked loop (PL-EPLL) is used for estimation of phase and frequency of grid voltages.

\section{ACKNOWLEDGMENT}

The authors would show their regard towards the MIETY, DST, Govt. of India, and EPSRC- EP/K03619X/1 for sponsoring this work under grant number: RP03391G.

\section{REFERENCES}

[1] R. Atia and N. Yamada, "Sizing and Analysis of Renewable Energy and Battery Systems in Residential Microgrids," IEEE Trans. Smart Grid, vol. 7, no. 3, pp. 1204-1213, May 2016.

[2] L. Igualada, C. Corchero, M. Zambrano and F. Heredia, "Optimal Energy Management for a Residential Microgrid Including a Vehicle-toGrid System," IEEE Trans. Smart Grid, vol. 5, no. 4, pp. 2163-2172, July 2014

[3] Q. Sun, J. Zhou, J. M. Guerrero and H. Zhang, "Hybrid ThreePhase/Single-Phase Microgrid Architecture With Power Management Capabilities," IEEE Trans. Power Electron., vol. 30, no. 10, pp. 59645977, Oct. 2015.

[4] D. Aviles, J. Pascual, L. Marroyo, P. Sanchis and F. Guinjoan, "Fuzzy Logic-Based Energy Management System Design for Residential GridConnected Microgrids," IEEE Trans. Smart Grid, vol. 9, no. 2, pp. 530543, March 2018.

[5] Z. Arani, S. Taher, A. Ghasemi and M. Shahidehpour, "Application of Multi-Resonator Notch Frequency Control for Tracking the Frequency in Low Inertia Microgrids Under Distorted Grid Conditions," IEEE Trans. Smart Grid, vol. 10, no. 1, pp. 337-349, Jan. 2019.
[6] X. Guo, W. Wu and Z. Chen, "Multiple-Complex Coefficient-FilterBased Phase-Locked Loop and Synchronization Technique for ThreePhase Grid-Interfaced Converters in Distributed Utility Networks," IEEE Trans. Ind. Electronics, vol. 58, no. 4, pp. 1194-1204, April 2011.

[7] S. Gude and C. Chu, "Three-Phase PLLs by Using Frequency Adaptive Multiple Delayed Signal Cancellation Prefilters Under Adverse Grid Conditions," IEEE Trans. Industry Applications, vol. 54, no. 4, pp. 38323844, July-Aug. 2018.

[8] Z. Zhang, Y. Yang, F. Blaabjerg and R. Ma, "Challenges to grid synchronization of single-phase grid-connected inverters in ZeroVoltage Ride-Through Operation," 2nd IEEE Annual Southern Power Electronics Conference (SPEC), Auckland, 2016, pp. 1-6.

[9] D. Yazdani, A. Bakhshai, G. Joos and M. Mojiri, "A Nonlinear Adaptive Synchronization Technique for Grid-Connected Distributed Energy Sources," IEEE Trans. Pwr Elec., vol. 23, pp. 2181-2186, July 2008.

[10] S. Kumar and B. Singh, "Seamless transition of three phase microgrid with load compensation capabilities," IEEE Ind. Appli. Society Annual Meeting, Cincinnati, OH, 2017, pp. 1-9.

[11] S. Kumar and B. Singh, "A Multipurpose PV System Integrated to a Three-Phase Distribution System Using an LWDF-Based Approach," IEEE Trans. Power Electron., vol. 33, no. 1, pp. 739-748, Jan. 2018.

[12] IEEE Standard for Interconnection and Interoperability of Distributed Energy Resources with Associated Electric Power Systems Interfaces, IEEE Std. 1547, 2018.

[13] F. Ding, P. Li, B. Huang, F. Gao, C. Ding and C. Wang; "Modeling and simulation of grid-connected hybrid photovoltaic/battery distributed generation system," in Proc. CICED, Nanjing, 2010, pp. 1-10.

[14] B. Singh, A. Chandra, and K. Al-Haddad, Power Quality: Problems and Mitigation Techniques. Hoboken, NJ, USA: Wiley, Jan. 2015.

[15] S. Kumar and B. Singh, "Multi-Objective Single-Stage SPV System Integrated to 3P4W Distribution Network Using DMSI-Based Control Technique," IEEE Trans. Ind. Appli., vol. 54, pp. 2656-2664, 2018.

[16] A. Yazdavar, M. Azzouz and E. El-Saadany, "A Novel Decentralized Control Scheme for Enhanced Nonlinear Load Sharing and Power Quality in Islanded Microgrids," IEEE Trans. Smart Grid, vol. 10, no. 1, pp. 29-39, Jan. 2019.

[17] S. Kumar and B. Singh, "Seamless Operation and Control of Single Phase Hybrid PV-BES-Utility Synchronized System" IEEE Trans. Ind. Appli., vol. 55, no. 2, pp. 1072-1082, March-April 2019.

[18] IEEE Recommended Practices and Requirements for Harmonic Control in Electrical Power Systems," IEEE Std. 519-1992, 1993.

[19] B. Widrow, M.E. Hoff, Adaptive switching circuits, STANFORD UNIV CA STANFORD ELECTRONICS LABS, 1960.

[20] M. Ghartemani, S. Khajehoddin, P. Jain, and A. Bakhshai, "Problems of startup and phase jumps in PLL systems," IEEE Trans. Power Electron., vol. 27, no. 4, pp. 1830-1838, Apr. 2012.

[21] V. Staudt, "Fryze - Buchholz - Depenbrock: A time-domain power theory," International School on Nonsinusoidal Currents and Compensation, Lagow, 2008, pp. 1-12.

[22] M. Ghartemani, "Linear and Pseudolinear Enhanced Phased-Locked Loop (EPLL) Structures," IEEE Trans. Ind. Electronics, vol. 61, no. 3, pp. 1464-1474, March 2014.

[23] J. Strack, I. Carugati, P. Donato, S. Maestri, C. Orallo, G. Mauro and D. Carrica "Three-phase voltage events classification algorithm based on Fortescue theorem," IEEE Biennial Congress of Argentina (ARGENCON), San Miguel de Tucumán, Argentina, 2018, pp. 1-8.

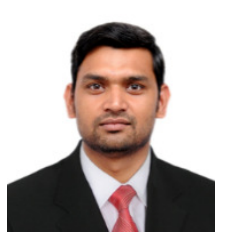

Shailendra Kumar (S'15, M'17) was born in Mahoba, India, in 1988. He received B.Tech. Degree in electrical and electronics engineering from Uttar Pradesh Technical University, Lucknow, India, in 2010, and the M.Tech. Degree in power electronics, electrical machine and drives (PEEMD) from the Indian Institute of Technology, Delhi, India, in 2015. He has completed his Ph.D. degree in department of electrical engineering from the Indian Institute of Technology Delhi, New Delhi, India on 16 May, 2019. Currently, He is working as a PostDoctoral Research Associate at Khalifa University (Petroleum Institute of Research Centre). His research interests include power quality, grid integration, custom power devices, microgrid and renewable energy. Mr. Kumar is recipient of POSOCO power system award (in Master as well as in Doctoral categories) in 2016 and 2019. He is also a recipient of Prof. Som Nath Mahendra Student Travel Awards for the PEDES 2018 conference and the IEEE UPCON Best Paper Award in 2016 and 2018. 


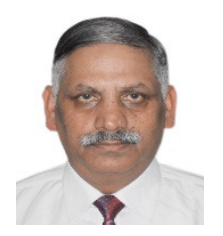

Bhim Singh (SM'99, F'10) was born in Rahamapur, Bijnor (UP), India, in 1956. He has received his B.E. (Electrical) from the University of Roorkee (Now IIT Roorkee), India, in 1977 and his M.Tech. (Power Apparatus \& Systems) and $\mathrm{Ph} . \mathrm{D}$. from the Indian Institute of Technology Delhi, India, in 1979 and 1983, respectively.

In 1983, he joined the Department of Electrical Engineering, University of Roorkee, as a Lecturer. He became a Reader there in 1988. In December 1990, he joined the Department of Electrical Engineering, IIT Delhi, India, as an Assistant Professor, where he has become an Associate Professor in 1994 and a Professor in 1997. He has been ABB Chair Professor from September 2007 to September 2012. He has also been CEA Chair Professor from October 2012 to September 2017. He has been Head of the Department of Electrical Engineering at IIT Delhi from July 2014 to August 2016. Since, August 2016, he is the Dean, Academics at IIT Delhi. He is JC Bose Fellow of DST, Government of India since December 2015. Prof. Singh is the Chairman of BOG, Maulana Azad National Institute of Technology, Bhopal, since 3rd July 2018 for 3 Years and Non-official Independent Director, NTPC Limited, since 17th July 2018 for 3 Years. He is CEA Chair Professor since January 2019. Prof. Singh has guided 74 Ph.D. dissertations, and 166 M.E./M.Tech./M.S.(R) theses. He has been filed 38 patents. He has executed more than eighty sponsored and consultancy projects. He has co-authored a text book on power quality: Power Quality Problems and Mitigation Techniques published by John Wiley \& Sons Ltd. 2015. His areas of interest include solar PV grid interface systems, microgrids, power quality monitoring and mitigation, solar PV water pumping systems, improved power quality AC-DC converters, power electronics, electrical machines, drives, flexible alternating transmission systems, and high voltage direct current systems.

Prof. Singh is a Fellow of the Indian National Academy of Engineering (FNAE), The Indian National Science Academy (FNA), The National Academy of Science, India (FNASc), The Indian Academy of Sciences, India (FASc), The World Academy of Sciences (FTWAS), Institute of Electrical and Electronics Engineers (FIEEE), the Institute of Engineering and Technology (FIET), Institution of Engineers (India) (FIE), and Institution of Electronics and Telecommunication Engineers (FIETE) and a Life Member of the Indian Society for Technical Education (ISTE), System Society of India (SSI), and National Institution of Quality and Reliability (NIQR).

$\mathrm{He}$ has received Khosla Research Prize of University of Roorkee in the year 1991. He is recipient of JC Bose and Bimal K Bose awards of The Institution of Electronics and Telecommunication Engineers (IETE) for his contribution in the field of Power Electronics. He is also a recipient of Maharashtra State National Award of Indian Society for Technical Education (ISTE) in recognition of his outstanding research work in the area of Power Quality. He has received PES Delhi Chapter Outstanding Engineer Award for the year 2006. Professor Singh has received Khosla National Research Award of IIT Roorkee in the year 2013. He is a recipient of Shri Om Prakash Bhasin Award-2014 in the field of Engineering including Energy \& Aerospace. Professor Singh has received IEEE PES Nari Hingorani Custom Power Award-2017. He is also a recipient of "Faculty Research Award as a Most Outstanding Researcher" in the field of Engineering-2018 of Careers-360, India. He has received Sulochana \& Colonel A Krishnaswami VrC VSM** Faculty Lifetime Research Award-2018 for overall research contribution at IIT Delhi.

$\mathrm{He}$ has been the General Chair of the 2006 IEEE International Conference on Power Electronics, Drives and Energy Systems (PEDES'2006), General CoChair of the 2010 IEEE International Conference on Power Electronics, Drives and Energy Systems (PEDES'2010), General Co-Chair of the 2015 IEEE International Conference (INDICON'2015), General Co-Chair of 2016 IEEE International Conference (ICPS'2016) held in New Delhi, General Co-Chair of 2017 National Power Electronics Conference (NPEC) held in Pune.

Prof. Singh has been Chair, PES-IAS Delhi Chapter for 2005-2010, (PES-IAS Delhi Chapter won Outstanding Chapter Award-2005 Large and High Performance Chapter Award Every Year). Prof. Singh has been Chair, PELSIES Delhi Chapter 2007-2010 and Founder Chair, PELS-IES Delhi Chapter. He has been Chair of IEEE Delhi Section for 2012-2014.

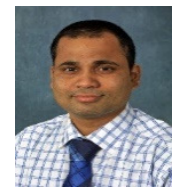

Bikash C. Pal (M'00-SM'02-F'13) received B.E.E. (with honors) degree from Jadavpur University, Calcutta, India, M.E. degree from the Indian Institute of Science, Bangalore, India, and Ph.D. degree from Imperial College London, London, U.K., in 1990, 1992, and 1999, respectively, all in electrical engineering. Currently, he is a Professor in the Department of Electrical and Electronic Engineering, Imperial College London. . His current research interests include renewable energy modelling and control, state estimation, and power system dynamics. He is Vice President Publications, IEEE Power \& Energy Society. He was Editor-in-Chief of IEEE
Transactions on Sustainable Energy (2012-2017) and Editor-in-Chief of IET Generation, Transmission and Distribution (2005-2012) and is a Fellow of IEEE for his contribution to power system stability and control.

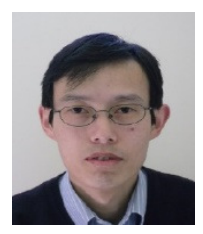

Lie Xu (M’03-SM'06) received the B.Sc. degree in Mechatronics from Zhejiang University, Hangzhou, China, in 1993, and the Ph.D. degree in Electrical Engineering from the University of Sheffield, Sheffield, UK, in 2000.

He is currently a Professor at the Department of Electronic \& Electrical Engineering, University of Strathclyde, Glasgow, UK. He previously worked in Queen's University of Belfast and ALSTOM T\&D, Stafford, UK. His research interests include power electronics, wind energy generation and grid integration, and application of power electronics to power systems. He is an Editor of IEEE Transactions on Power Delivery and IEEE Transactions on Energy Conversion.

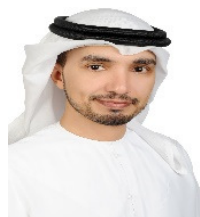

Ahmed Al-Durra received his $\mathrm{PhD}$ in ECE from Ohio State University in 2010. He is an Associate Professor in the ECE Department at Khalifa University, UAE. His research interests are applications of control and estimation theory on power systems stability, micro and smart grids, renewable energy systems and integration, and process control. He has one US patent, one edited book, 12 book chapters, and over 170 scientific articles in top-tier journals and refereed international conference proceedings. He has supervised/co-supervised over 20 $\mathrm{PhD} /$ Master students. He is leading the Energy Systems, Control \& Optimization Lab at ADNOC Research \& Innovation Center and an Editor for IEEE Transactions on Sustainable Energy and IEEE Power Engineering Letters. Dr. Al-Durra is the winner of Khalifa Award for Education Distinguished University Professor in Scientific Research (2019). 